economic and user issues and the other half to a compendium of appendices comprising legislative, judicial and patent documents. Nevertheless, the book offers a fascinating insight into the constitutional procedures by which such contentious matters are handled in the United States, a country that is far ahead of Europe. Despite the highly vocal animal-rights movement - with such notable advocates as Jeremy Rifkin - the US government has moved fast to protect the interests of inventors, farmers and other consumers.

Baruch Brody contributes a useful essay on the moral and ethical objections to patenting animals, reaching the conclusion that the opponents "must give us some reason to support (and accept the radical implications of) their rethinking the entire relation between humanity and the natural order". Robert Foote examines the implications of the new technology for animal science, and proposes that cryogenic embryo banks can solve the legal requirement to deposit examples of the patented product. Another distinguished animal scientist, William Hansel, discusses the likely impact of transgenic farm animals, and the economic consequences are further explored by Robert Milligan and William Lesser, who particularly welcome the major funding by the private sector of biotechnology centres in US universities and conclude that "royalties are necessary to encourage the needed investment in animal biotechnology research".

Pages 161-171 represent the heart of the book, for they contain US Patent No. 4736866, Leder et al., dated 12 April 1988, entitled "Transgenic Non-Human Animals". Anyone interested in molecular biology or genetic manipulation must be stirred by the historic precedent created by "oncomouse", the Harvard mouse containing a recombinant activated oncogene sequence for use in cancer research. Equally absorbing is the account of the second session of the hundredth US Congress on 26 August, when the gentleman from Wisconsin, Mr Kastenmeier, presented the Report of the Committee of the Judiciary on the Transgenic Animal Patent Reform Act. This report embodies a formidable review of the relevant science and technology amid a welter of submissions from civil-rights groups and patent lawyers. A letter from the White House urges acceptance of animal patents in the national economic interest because "Ten countries now permit animal patents, including Japan and Canada, while another 53 have not prohibited the granting of patents." Leaning on legislators is a well-recognized Top People sport in Britain too.

Sir Barry Cross is Secretary of the Zoological Society of London and was Director of the AFRC Institute of Animal Physiology and Genetics Research, Babraham, Cambridge CB2 4AT, UK.

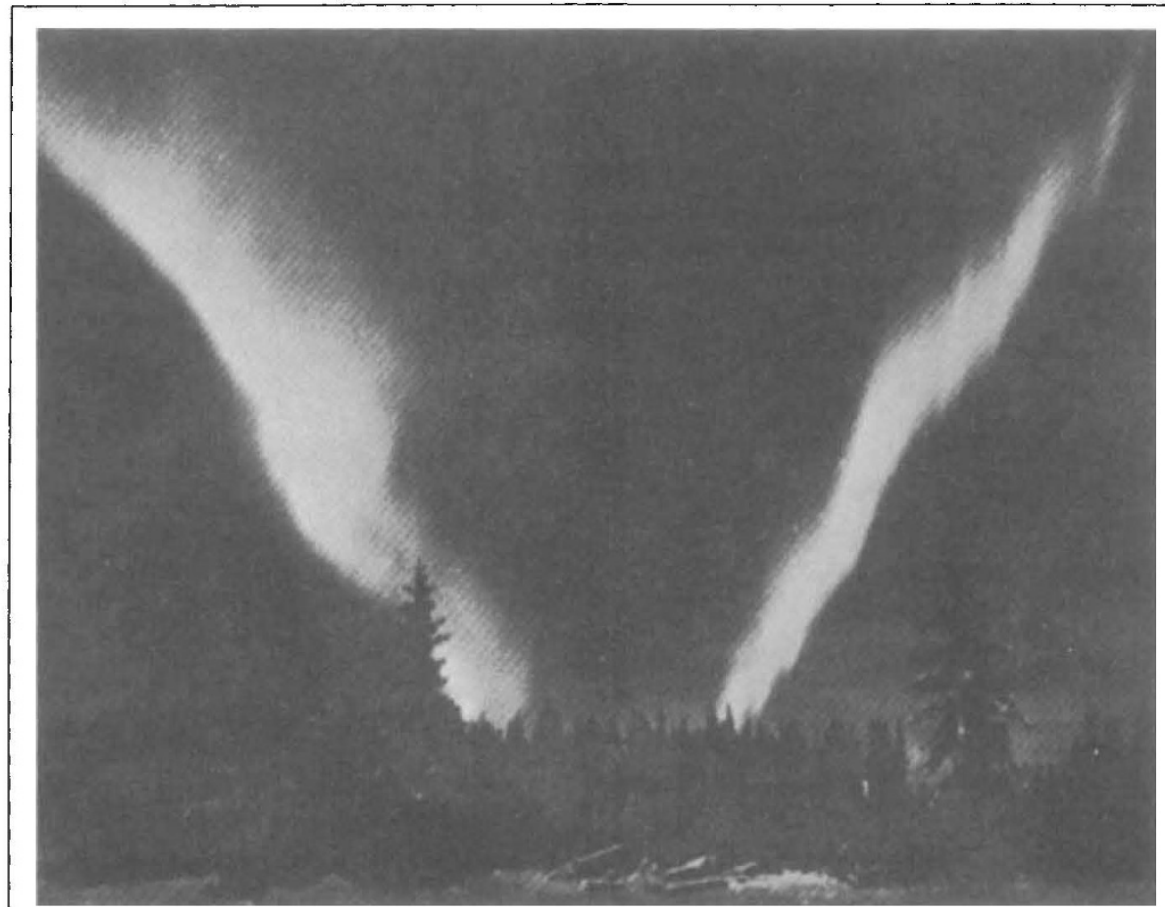

Bright lights - auroras are the result of ionization of earth's atmospheric gases, caused by solar electrons channelled there by the earth's magnetic field, at altitudes of 100 to $200 \mathrm{~km}$ above the magnetic poles. The picture here is reproduced from The Scientific Companion by C. Emiliani. Published by Wiley, 1988 , and now available in paperback, price $\$ 14.95, £ 9.95$.

\section{Thyroid gap}

Reg Hall

The Story of lodine Deficiency: An International Challenge in Nutrition. By Basil S. Hetzel. Oxford University Press: 1989. Pp. 236. Hbk £18.50, \$35; pbk £6.95.

BASIL Hetzel is one of the pioneers in the field of iodine deficiency. He has studied the problem as a professor of medicine, as a public health administrator and as an epidemiologist in the field. In this concise book he highlights the present situation on iodine deficiency, which even today is a hazard for nearly a billion people. Hetzel has collaborated with many eminent workers in the field, notably John Stanbury, V. Ramalingaswami and John Dunn, and with them has set up the International Council for Control of Iodine Deficiency Disorders, a body which aims to close the gap between current knowledge in the field and its application.

Part I of Hetzel's book deals with the understanding of iodine deficiency and introduces the author's concept of the iodine deficiency disorders, comprising goitre, still births and miscarriages, neonatal and juvenile thyroid deficiency, dwarfism, mental defects, deaf mutism and spastic weakness and paralysis, as well as lesser degrees of loss of physical and mental function. All these defects result from lack of thyroid hormone, of which iodine is an essential constituent, and all of them can be prevented by adequate iodine intake.
In part II, Hetzel deals with the international control of iodine deficiency disorders by iodine supplementation. He highlights the logistical problems of achieving adequate iodine intake in many parts of the world. In the West, iodine deficiency disorders have been prevented by methods such as the iodine supplementation of salt, or sometimes by chance, for example in the United Kingdom where cattle food supplements in winter provide a variably large iodine intake in milk and dairy foods. But deficiency still exists in parts of Europe, such as southern West Germany, where compulsory iodine supplementation is forbidden by law. In the developing world, progress remains slow; large populations in China, India, Indonesia and Africa remain iodine deficient.

In part III the author summarizes the present status of iodine deficiency disorders and their control in Europe, Africa, Latin America and Asia. He concludes that the chances of significant progress for correction of these disorders will depend on the "motivation of national governments", the financial resources and the availability of trained manpower.

Altogether this is a splendid book by an acknowledged authority in the field. It will appeal to a wide audience of physicians, nutritionists, field workers and epidemiologists as a concise, simple introduction to the problem of iodine deficiency.

Reg Hall was Professor of Medicine at the University of Wales College of Medicine, Heath Park, Cardiff CF4 4XN, UK. 